\title{
Smart Touch Radiofrequency Catheter Ablation versus Cryoballoon Ablation of Pulmonary Veins in Patients with Paroxysmal Atrial Fibrillation
}

\author{
Walid Shehata Hassan*, Sherief Hamed Zaky, Khaled Hussein Mohamed, Moataz Mohammed Ibrahim
}

Department of Critical Care Medicine, Cairo University, Giza, Egypt

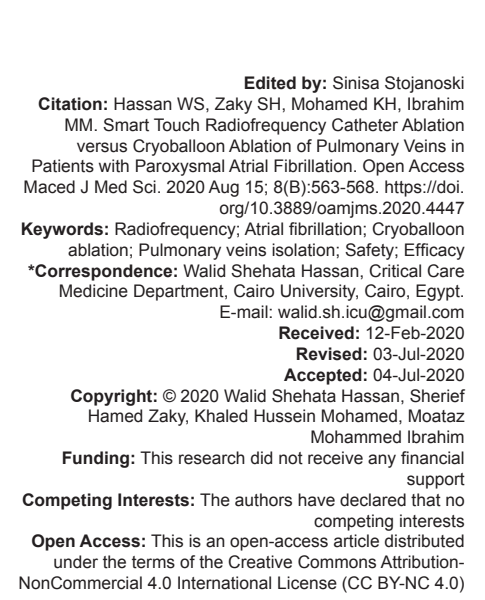

\section{Introduction}

Atrial fibrillation (AF) is the most common sustained supraventricular tachyarrhythmia [1]. Catheter ablation strategies for the treatment of AF have been in a process of continuous development since 1996, and catheter ablation is now regarded as an effective and safe therapeutic option. Pulmonary vein isolation (PVI) is the cornerstone of catheter ablation techniques for the treatment of paroxysmal AF (PAF), with significantly improved efficacy compared to antiarrhythmic drugs [2], [3] However, AF recurrence after a single procedure remains relatively frequent and in most of cases is related to $\mathrm{PV}$ reconnections [4]. This may reflect the difficulty in achieving effective transmural, continuous, and longlasting lesions when performing PVI [5], [6]. Newer technologies are being developed with efforts to improve outcomes in patients undergoing AF ablations. The contact force (CF) between catheter tip and PVs tissue has been shown to be a major influencing factor in achieving effective and continuous tissue lesions [7], [8], [9], [10]. Accordingly, novel technologies for AF catheter ablation have recently focused on the optimization of the contact between catheter tip and target tissue. On the one hand, the CF-sensing technology has been recently developed, allowing continuous CF monitoring during ablation [11]. On the other hand, second generation of cryoballoon (CB), the Arctic Front AdvanceTM, has been developed to optimize lesions in various settings of $P V$ anatomies [12], [13], [14]. However, the question arises in which PAF patients whether PVI can be done using radiofrequency ablation with $\mathrm{CF}$ sensing catheter or with $\mathrm{CB}$ ablation. In the present study, we sought to compare the safety and efficacy of CF-sensing RF catheters with second-generation $\mathrm{CB}$ catheter in the setting of PAF catheter ablation.

\section{Methods} \section{collection}

\section{Study type, study population, and data}

This is a prospective non-randomized controlled clinical trial that was conducted during the 
period between January 2016 and June 2018 in Critical Care Medicine Department - Cairo University. The primary endpoint of this study is to compare the safety and efficacy of catheter ablation of PAF using two different technologies (RF ablation using CF catheters vs. cryoballoon ablation) as a first experience with those two new technologies in our center. Secondary end points consisted of (1) freedom from AF or atrial flutter/tachycardia lasting $>30 \mathrm{~s}$ at 12 months after a 3-month blanking period, following a single ablation procedure without the use of antiarrhythmic therapy (2) determinants of fluoroscopy time, and (3) types and frequencies of procedure-related complications. Our study design involved 25 patients in each group. Patients were eligible if they presented with PAF refractory to at least one antiarrhythmic drug from Class I or III undergoing first PVI procedure. Exclusion criteria were in need of additional lines (i.e., roof and mitral isthmus) or ablation of complex-fractionated electrograms during the procedure. Importantly, patient selection for one or the other energy group was not made depending on the patient's characteristics (i.e., PV anatomy) but based on physician discretion performing the ablation procedure. Specifically, each electrophysiology physician used always the same ablation energy (either RF or cryothermal) for all his AF ablations, regardless of $\mathrm{PV}$ anatomy. All patients provided an informed written consent before the procedure.

\section{Ablation procedure details: Common Elements between $C F$ and $C B$ Groups}

Transesophageal echocardiography was done 24-48 $\mathrm{h}$ before the procedure to determine left atrial (LA) dimensions and to exclude the presence of a potential LA thrombus. Vitamin-K antagonists were not interrupted before the procedure with INR $<3$. New oral anticoagulants were not interrupted before the procedure. All procedures were performed under a mild conscious or deep sedation depending on the physician performing the procedure. A decapolar catheter was positioned in the coronary sinus, through a transfemoral venous access. A single or double transseptal puncture was performed under fluoroscopic guidance. A bolus of unfractionated heparin (UFH) was administered immediately after the transseptal puncture and infusion was titrated to maintain activated clotting time (ACT) of 300-350 s for the duration of the procedure. No esophageal monitoring was done during the procedure. ACT was then repeated every 30 min and UFH was given accordingly to maintain the measurements within target. At the end of procedure, protamine was given, at operator's discretion, to reverse the effect of heparin. Catheters were removed and hemostasis was ensured. Procedure time (from skin puncture to removal of sheaths) and fluoroscopy time were recorded.

\section{Specific procedural details: CF group}

A circumferential mapping catheter (CMC; LassoTM; Biosense Webster) was introduced into the LA using an 8.5 Fr long sheath. The ablation catheter was advanced into the LA either sequentially after removing the CMC (in case of single transseptal puncture) or simultaneously with the CMC (in case of double transseptal punctures). The ablation catheter and the CMC were used to collect LA geometry using the electroanatomic mapping (EAM) system. The ablation strategy consisted of PVI using two wide antral circumferential RF ablations across ipsilateral PVs, without additional adjunctive LA ablation. Power controlled RF ablation lesions were delivered with 30-35Wpower (flow rate, 17-20 $\mathrm{mL} / \mathrm{min}$ ); the endpoint was elimination of the local bipolar EGM with 20-40 $\mathrm{s}$ lesions, or with force-time integral $(\mathrm{FTI})>400 \mathrm{~g} \mathrm{~s}$. A lower power 20-25 W (flow rate, $17 \mathrm{~mL} / \mathrm{min}$ ) and duration settings were used for ablation on the posterior LA wall close to the esophagus. CF data were available to the operator throughout the procedure. The aim was to achieve a mean CF of at least $10 \mathrm{~g}$ during RF application. The upper limit defined was $50 \mathrm{~g}$ force [7]. PVI was first performed anatomically, the Lasso catheter being used only after completion of anatomic $\mathrm{PVI}$ to confirm full PV disconnection. This was done by testing both entrance and exit block (bidirectional block). In the event, complete disconnection was not achieved (failure of either exit or entrance block), PVI was completed with Lasso guidance to eliminate all points of residual $\mathrm{PV}$ connection. Carina ablations were performed when PV isolation could not be achieved with antral isolation. Typically carina ablation targeted the earliest potential for both ipsilateral PVs identified at the carina. At the end of the procedure, a waiting period of at least 20 min was performed, to assess for dormant LA-PV connections.

\section{Specific procedural details: CB group}

Pulmonary vein angiography was done for all patients after the transseptal puncture to assess PVs number and anatomy. A 14-Fr deflectable sheath (FlexCath, Medtronic) was advanced into the LA through the transseptal puncture. Then, the Arctic Front AdvanceTM balloon was introduced into the sheath, inflated, and advanced to the ostium of each PV. Before cryoenergy delivery, the occlusion of each PV was assessed with a venous angiography. Ablation of PV antra was performed with two applications of $240 \mathrm{~s}$ per vein. Continuous monitoring of the phrenic nerve during ablation of the right PVs was systematically performed by pacing the right phrenic nerve with a quadripolar catheter in the superior vena cava. PVI was either assessed continuously using the circular Achieve Catheter (Medtronic) during CB freezing or traditionally using a CMC (Lasso, Biosense Webster) after two applications. If the PV remained connected, 
additional applications were performed using different angulations. PVI was finally checked 20 min after the last CB ablation.

\section{Standardized follow-up}

A transthoracic echocardiography was performed immediately after the procedure and before hospital discharge. Patients were followed for a total of 12 months. Patients were evaluated before hospital discharge, as well as at 1, 3, 6, 9, and 12 months after the procedure. Information collected during follow-up included clinical symptoms, a 12-lead electrocardiogram (ECG) and a 24-h Holter monitoring at each visit. A blanking period of 3 month has been chosen in this study during which antiarrhythmic drugs were maintained. After the blanking period, all antiarrhythmic drugs were stopped. If there was documented recurrence of symptomatic AF after this time interval and the patient required antiarrhythmic drug therapy, a previously ineffective but tolerated Class I or Class III drug was the preferred option. Anticoagulation strategy after the first 3 months was based on the CHA2DS2Vasc and HAS-BLED scores [15].

\section{Procedural endpoint}

Procedural endpoint was PV isolation confirmed by entry and exit block after a waiting time of $20 \mathrm{~min}$. The specific differences of the two used therapeutic approaches are described above.

\section{Study endpoints}

The long-term efficacy endpoint was freedom from any atrial arrhythmia lasting more than $30 \mathrm{~s}$ for up to 12 months after a single procedure. This was achieved by Holter monitoring at $1,3,6,9$, and 12 months or by 12-lead ECG in the case of symptomatic palpitation at clinical visits. Patients with recurrence of AF after the blanking period and in the absence of antiarrhythmic drugs were classified as having a relapse. The safety endpoint was a comparison of significant adverse events between groups.

\section{Statistical methods}

Data were coded and entered using the statistical package SPSS version 25. Data were summarized using mean and standard deviation for quantitative variables and frequencies (number of cases) and relative frequencies (percentages) for categorical variables. Comparisons between groups were done using unpaired t-test. For comparing categorical data, Chi-square test was performed. Exact test was used instead when the expected frequency is $<5$. Correlations between quantitative variables were done using Pearson correlation coefficient. $p=0.05$ were considered as statistically significant.

\section{Results}

\section{Patient characteristics}

Population characteristics are detailed in Table 1. Overall, 50 patients were included: 25 in the CF group underwent PVI using the Thermocool SmartTouchTM catheter and 25 in the CB group. Cavotricuspid isthmus ablation was performed in 2 patients $(8 \%)$ of the CF group. The mean age of patients was $46.9+11.72$ years. The proportion of women was $36 \%$; the LA size in the parasternal long axis was $40.5 \pm$ $4.75 \mathrm{~mm}$. Mean duration of documented AF was $3 \pm 2.3$ years and was not significantly different between the two groups. Mean CHA2DS2-VASc score $1.4 \pm 1.3$ and mean HAS-BLED $1.4 \pm 0.6$ without significant difference between both groups. Overall, no significant baseline differences were observed between the CF and CB. All the patients continued on antiarrhythmic and on anticoagulation therapy for 3 months post-ablation.

Table 1: Baseline characteristics of patients

\begin{tabular}{|c|c|c|c|c|}
\hline Demographic data & All $n=50$ & $\begin{array}{l}\text { Group } 1(\mathrm{CB}) \\
\mathrm{n}=25(50 \%)\end{array}$ & $\begin{array}{l}\text { Group } 2(\mathrm{CF}) \\
\mathrm{n}=25(50 \%)\end{array}$ & $p$-value \\
\hline${ }^{*}$ Age (years) & $46.9 \pm 11.7$ & $47.9 \pm 11.6$ & $45.9 \pm 12.35$ & 0.714 \\
\hline${ }^{*}$ Gender $(F)^{*}(\%)$ & $18(36)$ & $10(40)$ & $8(32)$ & $>0.05$ \\
\hline *Hypertension & $11(22)$ & $6(24)$ & $5(20)$ & $>0.05$ \\
\hline${ }^{*} \mathrm{DM}$ & $12(24)$ & $7(28)$ & $5(20)$ & $>0.05$ \\
\hline *CAD & $3(6)$ & $2(8)$ & $1(4)$ & $>0.05$ \\
\hline *HF & $3(6)$ & $1(4)$ & $2(8)$ & $>0.05$ \\
\hline *Asthma & $1(2)$ & $0(0)$ & $1(4)$ & $>0.05$ \\
\hline *LAD & $4.05 \pm 0.475$ & $4.1 \pm 0.38$ & $4.09 \pm 0.57$ & 0.716 \\
\hline *LVEF\% & $61.65 \pm 6.7$ & $61.2 \pm 5.73$ & $62.1 \pm 7.8$ & 0.773 \\
\hline${ }^{*}$ CHA2DS2-VASC score & $1.4 \pm 1.3$ & $1.5 \pm 1.3$ & $1.3 \pm 1.3$ & 0.308 \\
\hline *HAS-BLED & $1.4 \pm 0.6$ & $1.5 \pm 0.6$ & $1.4 \pm 0.5$ & 0.243 \\
\hline${ }^{*} \mathrm{AF}$ duration (years) & $3 \pm 2.3$ & $3 \pm 2.5$ & $3 \pm 2.1$ & 0.7 \\
\hline
\end{tabular}

\section{Procedural results}

Procedural data are detailed in Table 2. All PVs in both groups were successfully isolated during the procedure. No complementary RF applications were needed to achieve complete PVI in the CB group. Duration of the procedure was significantly lower in the CB group $(171.7 \pm 15.24$ vs. $199.3 \pm 18.94 \mathrm{~min}$, $p=0.002$ ), however, with a longer duration of fluoroscopy and X-ray exposure in the CB group than the CF group but statistically non-significant difference (58.60 \pm 11.57 vs. $48.7 \pm 13.86 \mathrm{~min}$ and $6273 \pm 4934 \mathrm{cGy} \mathrm{cm}{ }^{2}$ vs. 6853 \pm 5069 cGy cm${ }^{2}, p=0.1$ and $p=0.2$, respectively). Mean CF observed in the CF group was $18.4 \mathrm{~g} \pm 35$.

Table 2: Procedure data in both groups

\begin{tabular}{llll}
\hline Procedure data & CB group & CF group & p-value \\
\hline Time from puncture to transseptal $(\mathrm{min})$ & $26.80 \pm 6.32$ & $17.6 \pm 4.43$ & 0.001 \\
Procedure time (min) & $171.70 \pm 15.24$ & $199.3 \pm 18.94$ & 0.002 \\
Time of mapping PVs/LA (min) & $27.90 \pm 6.3$ & $27.6 \pm 7.07$ & 0.921 \\
Fluoroscopy time (min) & $58.60 \pm 11.57$ & $48.7 \pm 13.86$ & 0.100 \\
X-ray exposure(cGy cm ${ }^{2}$ ) & $6273 \pm 4934$ & $6853 \pm 5069$ & 0.22 \\
\hline CF: Contact force, CB: Cryoballoon, LA: Left atrial. & & &
\end{tabular}




\section{Periprocedural complications}

The total number of complications in both groups was similar: $2(8 \%)$ in each group. Transient phrenic nerve palsy occurred in one patient $(4 \%)$ of the CB group with normal diaphragmatic function at the end of the procedure. No patient died in either group from a procedural complication but severe complications occurred in 3 patients $(6 \%)$. Pericardial effusion and tamponade due to perforation of the left atrial appendage (LAA) occurred only in one patient in the CF group and this required surgical repair of the LAA (for this patient, PVI was already achieved). Entrapment of circular mapping catheter into the mitral valve chordae occurred in one patient in the CF group which required surgical intervention (for this patient, PVI was already achieved). Embolic stroke occurred in one patient of the CB group post ablation, diagnosed by MRI brain with diffusion.

\section{Twelve-month follow-up}

All patients were followed up for 12 months after the procedure.

AF recurrence occurred in $7(28 \%)$ patients in the CF group and in 9 (36\%) patients in the CB group. All recurrences were in the form of AF except for one patient (in CF group) whose recurrence was in the form of atrial flutter.

Older patients were more likely to have AF recurrence than those with younger age $(55.00+7.85$ vs. $42.54+11.30, p=0.019)$. Patients with higher left ventricular ejection fraction (LVEF)\% were less likely to have AF recurrence than those with lower LVEF\% $(64.46+5.52$ vs. $56.43+5.68, p=0.007)$. Furthermore, our study showed that recurrence in blanking period (first 3 months post-procedure) was found to precede most cases of later recurrence $(p=0.017)$.

\section{Discussion}

AF represents an important public health problem. Patients withAF haveanincreased long-term risk of stroke, heart failure, and all-cause mortality [16], [17], [18]. Catheter ablation has emerged as effective therapy for AF, especially when antiarrhythmic drugs (AADs) fail. Catheter ablation (CA) for symptomatic drug-refractory, PAF is a Class I/A treatment indication in the current guidelines [19], [20], [21]. When CA is necessary, PVI is the cornerstone of ablation for PAF and RF, CA is the traditional method of ablation [22]. The rationale for better RF lesions using higher CF is a larger electrodetissue contact area, allowing improved RF energy delivery to the myocardium. Subsequently, new RF catheters have embedded force-sensing technologies
(Thermocool SmartTouch ${ }^{\mathrm{TM}}$ and Tacticath $^{\mathrm{TM}}$ ) providing real-time CF monitoring, allowing for electrode-tissue contact optimization. During AF ablation procedures, CF monitoring permitted a reduction of $\mathrm{PV}$ chronic reconnection and an improvement of clinical outcomes by targeting a CF of at least $10 \mathrm{~g}$ (if possible $20 \mathrm{~g}$ ) and a FTI .400 g s for each RF application [10], [23], [24]. Finally, CF monitoring may increase procedure safety by avoiding high CF values, which are at higher risk of steam pop and cardiac perforation [7], [25]. On the other hand, AF ablation using cryotherapy has also evolved recently with dramatic $\mathrm{CB}$ improvements. Compared with the first generation $\mathrm{CB}$ (Arctic FrontTM), the second-generation CB (Arctic Front AdvanceTM) has twice as many injection ports (8), and these have been positioned more distally on the catheter's shaft resulting in a larger and more uniform zone of freezing on the CB surface. This resulted in improved procedural data (procedure duration, fluoroscopy time, time to $\mathrm{PVI}$ ) compared with the first-generation CB [26], [27], and in better clinical outcomes.

To the best of our knowledge, the present study is the first prospective, trial in Egypt evaluating the efficacy and safety of catheter ablation using two different technologies, RFCA with CF sensing catheters and CBCA for PAF patients' refractory to medical treatment. Specifically, the study examined the preferred ablation method for PVI as a second line treatment strategy in symptomatic PAF patients.

In this single center study, we demonstrated that new CF-sensing RF catheters and secondgeneration $C B$ have comparable efficacy in the setting of PAF ablation. A comparable proportion of patients in both groups (72\% in the CF group vs. $64 \%$ in the CB group) remained free from any atrial arrhythmia at 12 months after a single ablation procedure, free of antiarrhythmic drugs. The overall complication rates were equivalent with both technologies, but cryoablation led more frequently to transient phrenic nerve palsy, and RF ablation led more frequently to severe non-lethal complications. Procedure duration was slightly longer using RF than using cryoablation; these findings were already reported previously and probably account for the time required to create the three dimension (3D) EAM and to perform the pointby-point isolation of the PVs with the RF ablation catheters. If the use of CF-sensing RF catheter or second-generation $\mathrm{CB}$ catheter should be preferred over older models, the choice of either of the ablation energies (RF or cryothermal) for PAF ablation often depends on the operators' skills and habits, and on available material and associated costs. Our results suggest that both RF with CF-sensing and cryoenergy lead to comparable outcomes in non-selected patients, with a similar overall complication rate. Therefore, in case of PAF ablation, this study does not provide clues for a clear preference between RF and cryoablation. 


\section{Limitations}

We were very strict about inclusion and exclusion criteria, good selection of homogeneous patient criteria in both groups, and eradication of all potential biases that can affect our results; however, this study has several limitations. First, this is not a randomized trial and inclusion of the patients for one or the other group is potentially subject to significant bias.

Second, different operators and the presence of trainee with different experiences may affect recurrence rate, procedure duration, fluoroscopy time, and complication rate. Thirdly, follow-up was performed using systematic $24 \mathrm{~h}$-Holter ECGs and additional $24 \mathrm{~h}$-Holter ECGs in case of symptoms. This method may underestimate recurrence rates compared with implantable loop recorders. Fourth, the lack of CT angiography of left atrium or MRI of left atrium before ablation and its merging with 3D mapping system or during $\mathrm{CB}$ ablation was associated with prolonged total procedure duration, fluoroscopy time, and radiation exposure. Finally, this study is our first Egyptian experience with CF sensing catheters (Smart TouchTM) and $\mathrm{CB}$ ablation and we were in the growing curve of cryoablation.

\section{Conclusion}

The treatment of patients with symptomatic PAF who are refractory to antiarrhythmic drug therapy with catheter ablation became well established and seems to be safe and effective with RF or CB. By comparison, the $\mathrm{CB}$ procedure was significantly faster and less complex, which are important considerations when evaluating the preferred ablation method. The radiation exposure was higher in the $C B$ group but remained in a reasonable range when compared with RF cohort. More data are necessary to determine the preferred energy source for catheter ablation of PAF. At the moment, if the use of CF-sensing RF catheter or second-generation $\mathrm{CB}$ catheter should be preferred over older models, the choice of either of the ablation energies (RF or cryothermal) for PAF ablation often depends on the operators' skills and habits, and on available material and associated costs.

\section{References}

1. Feinberg WM, Blackshear JL, Laupacis A, Kronmal R, Hart RG. Prevalence, age distribution, and gender of patients with atrial fibrillation. Analysis and implications. Arch Intern Med. 1995;155(5):469-73. https://doi.org/10.1001/ archinte.1995.00430050045005

\section{PMid:7864703}

2. Wilber DJ, Pappone C, Neuzil P, De Paola A, Marchlinski F, Natale A, et al. Comparison of antiarrhythmic drug therapy and radiofrequency catheter ablation in patients with paroxysmal atrial fibrillation: A randomized controlled trial. JAMA 2010;303(4):333-40. https://doi.org/10.1001/jama.2009.2029

\section{PMid:20103757}

3. Packer DL, Mark DB, Robb RA, Monahan KH, Bahnson TD, Moretz $\mathrm{K}$, et al. Catheter ablation versus antiarrhythmic drug therapy for atrial fibrillation (CABANA) trial: Study rationale and design. Am Heart J. 2018;199:192-9. https://doi.org/10.1016/j. ahj.2018.02.015

\section{PMid:29754661}

4. Ouyang F, Antz M, Ernst S, Hachiya H, Mavrakis H, Deger FT, et al. Recovered pulmonary vein conduction as a dominant factor for recurrent atrial tachyarrhythmias after complete circular isolation of the pulmonary veins: Lessons from double Lasso technique. Circulation. 2005;111(2):127-35. https://doi. org/10.1016/j.accreview.2005.04.043

5. Verma A, Kilicaslan F, Pisano E, Marrouche NF, Fanelli $R$, Brachmann J, et al. Response of atrial fibrillation to pulmonary vein antrum isolation is directly related to resumption and delay of pulmonary vein conduction. Circulation. 2005;112(5):627-35. https://doi.org/10.1161/circulationaha.104.533190

PMid:16061753

6. Ouyang F, Tilz R, Chun J, Schmidt B, Wissner E, Zerm T, et al. Long-term results of catheter ablation in paroxysmal atrial fibrillation: Lessons from a 5-year follow-up. Circulation. 2010;122(23):2368-77. https://doi.org/10.1161/ circulationaha.110.946806

PMid:21098450

7. Yokoyama K, Nakagawa H, Shah DC, Lambert H, Leo G, Aeby $\mathrm{N}$, et al. Novel contact force sensor incorporated in irrigated radiofrequency ablation catheter predicts lesion size and incidence of steam pop and thrombus. Circ Arrhythm Electrophysiol. 2008;1(5):354-62. https://doi.org/10.1161/ circep. 108.803650

PMid: 19808430

8. Shah DC, Lambert $\mathrm{H}$, Nakagawa $\mathrm{H}$, Langenkamp A, Aeby $\mathrm{N}$, Leo $\mathrm{G}$. Area under the real-time contact force curve (forcetime integral) predicts radiofrequency lesion size in an in vitro contractile model. J Cardiovasc Electrophysiol. 2010;21(9):103843. https://doi.org/10.1111/j.1540-8167.2010.01750.x

\section{PMid:20367658}

9. Thiagalingam A, D'Avila A, Foley L, Guerrero JL, Lambert $\mathrm{H}$, Leo $G$, et al. Importance of catheter contact force during irrigated radiofrequency ablation: Evaluation in a porcine ex vivo model using a force-sensing catheter. J Cardiovasc Electrophysiol. 2010;21(7):806-11. https://doi. org/10.1111/j.1540-8167.2009.01693.x

PMid:20132400

10. Squara F, Latcu DG, Massaad Y, Mahjoub M, Bun SS, Saoudi N Contact force and force-time integral in atrial radiofrequency ablation predict transmurality of lesions. Europace. 2014;16(5):660-7. https://doi.org/10.1093/europace/euu068 PMid:24798957

11. Kuck KH, Reddy VY, Schmidt B, Natale A, Neuzil P, Saoudi N, et al. A novel radiofrequency ablation catheter using contact force sensing: Toccata study. Heart Rhythm. 2012;9(1):18-23. https://doi.org/10.1016/j.hrthm.2011.08.021 PMid:21872560

12. Liu CF. Pulmonary vein reconnection after cryoballoon ablation: Back to the drawing board. Heart Rhythm. 2010;7(2):191-2. PMid:20129296

13. Kubala M, Hermida JS, Nadji G, Quenum S, Traulle S, 
Jarry G. Normal pulmonary veins anatomy is associated with better AF-free survival after cryoablation as compared to atypical anatomy with common left pulmonary vein. Pacing Clin Electrophysiol. 2011;34(7):837-43. https://doi. org/10.1111/j.1540-8159.2011.03070.x PMid:21418249

14. Sorgente A, Chierchia GB, de Asmundis C, Sarkozy A, Namdar $M$, Capulzini $L$, et al. Pulmonary vein ostium shape and orientation as possible predictors of occlusion in patients with drug-refractory paroxysmal atrial fibrillation undergoing cryoballoon ablation. Europace. 2011;13(2):205-12. https://doi. org/10.1093/europace/euq388

PMid:20974756

15. Camm AJ, Lip GY, De Caterina R, Savelieva I, Atar D, Hohnloser SH, et al. 2012 focused update of the ESC guidelines for the management of atrial fibrillation: An update of the 2010 ESC guidelines for the management of atrial fibrillation-developed with the special contribution of the European heart rhythm association. Europace. 2012;14(10):1385-413. https:// doi.org/10.3410/f.718304414.793499785

PMid:22923145

16. Camm AJ, Kirchhof P, Lip GY, Schotten U, Savelieva I, Ernst S, et al. Guidelines for the management of atrial fibrillation: The task force for the management of atrial fibrillation of the European society of cardiology (ESC). Eur Heart J. 2010;31(19):2369429. https://doi.org/10.12968/bjca.2011.6.5.240

PMid:20802247

17. Benjamin EJ, Wolf PA, D'Agostino RB, Silbershatz H, Kannel WB, Levy D. Impact of atrial fibrillation on the risk of death: The Framingham heart study. Circulation. 1998;98(1):946-52.

PMid:9737513

18. Krahn AD, Manfreda J, Tate RB, Mathewson FA, Cuddy TE. The natural history of atrial fibrillation: Incidence, risk factors, and prognosis in the Manitoba follow-up study. Am J Med. 1995;98(5):476-84. https://doi.org/10.1016/ s0002-9343(99)80348-9

PMid: 7733127

19. January CT, Wann LS, Calkins H, Chen LY, Cigarroa JE, Cleveland JC Jr., et al. 2019 AHA/ACC/HRS focused update of the $2014 \mathrm{AHA} / \mathrm{ACC} / \mathrm{HRS}$ guideline for the management of patients with atrial fibrillation: A report of the American college of cardiology/American heart association task force on clinical practice guidelines and the heart rhythm society. Heart Rhythm. 2019;16(8):e66-93. https://doi.org/10.1161/ cir.0000000000000719

PMid:30703431

20. January CT, Wann LS, Alpert JS, Calkins H, Cigarroa JE, Cleveland JC Jr., et al. 2014 AHA/ACC/HRS guideline for the management of patients with atrial fibrillation: A report of the American college of cardiology/American heart association task force on practice guidelines and the heart rhythm society. J Am Coll Cardiol. 2014;64(21):e1-76. https://doi.org/10.1161/ cir.0000000000000719

PMid:24685669
21. Kirchhof P, Benussi S, Kotecha D, Ahlsson A, Atar D, Casadei B, et al. 2016 ESC Guidelines for the management of atrial fibrillation developed in collaboration with EACTS. Eur Heart J. 2016;37(38):2893-962.

22. Calkins H, Kuck KH, Cappato R, Brugada J, Camm AJ, Chen SA, et al. 2012 HRS/EHRA/ECAS expert consensus statement on catheter and surgical ablation of atrial fibrillation: Recommendations for patient selection, procedural techniques, patient management and follow-up, definitions, endpoints, and research trial design: A report of the heart rhythm society (HRS) task force on catheter and surgical ablation of atrial fibrillation. Developed in partnership with the European heart rhythm association (EHRA), a registered branch of the European society of cardiology (ESC) and the European cardiac arrhythmia society (ECAS); and in collaboration with the American college of cardiology (ACC), American heart association (AHA,) the Asia Pacific heart rhythm society (APHRS), and the society of thoracic surgeons (STS). endorsed by the governing bodies of the American college of cardiology foundation, the American heart association, the European cardiac arrhythmia society, the European heart rhythm association, the society of thoracic surgeons, the Asia Pacific heart rhythm society, and the heart rhythm society. Heart Rhythm. 2012;9(4):632-96. https://doi. org/10.1093/europace/eun122

PMid:22386883

23. Marijon E, Fazaa S, Narayanan K, Guy-Moyat B, Bouzeman A Providencia $\mathrm{R}$, et al. Real-time contact force sensing for pulmonary vein isolation in the setting of paroxysmal atrial fibrillation: Procedural and 1-year results. J Cardiovasc Electrophysiol. 2014;25(2):130-7. https://doi.org/10.1111/ jce.12303 PMid:24433324

24. Reddy VY, Shah D, Kautzner J, Schmidt B, Saoudi N, Herrera C, et al. The relationship between contact force and clinical outcome during radiofrequency catheter ablation of atrial fibrillation in the TOCCATA study. Heart Rhythm. 2012;9(11):1789-95. https:// doi.org/10.1016/j.hrthm.2012.07.016 PMid:22820056

25. Shah D, Lambert H, Langenkamp A, Vanenkov Y, Leo G, Gentil-Baron $\mathrm{P}$, et al. Catheter tip force required for mechanical perforation of porcine cardiac chambers. Europace. 2011;13(2):277-83. https://doi.org/10.1093/europace/euq403 PMid:21084361

26. Straube F, Dorwarth U, Schmidt M, Wankerl M, Ebersberger U, Hoffmann E. Comparison of the first and second cryoballoon: High-volume single-center safety and efficacy analysis. Circ Arrhythm Electrophysiol. 2014;7(2):29. https://doi.org/10.1161/ circep. 113.000899

PMid:24610739

27. Straube F, Dorwarth $U$, Vogt J, Kuniss $M$, Kuck $\mathrm{KH}$, Tebbenjohanns $\mathrm{J}$, et al. Differences of two cryoballoon generations: Insights from the prospective multicentre, multinational FREEZE cohort substudy. Europace. 2014;16(10):1434-42. https://doi.org/10.1093/europace/euu162 PMid:24994074 